\title{
Unmasking of Partial Diabetes Insipidus during Stress but Not Maintenance Dosing of Glucocorticoids in an Infant with Septo-Optic Dysplasia
}

\author{
Mala Puri, Anita Azam, and Karen J. Loechner \\ Division of Pediatric Endocrine, Department of Pediatrics, University of North Carolina, Chapel Hill, NC 27599, USA \\ Correspondence should be addressed to Mala Puri, mpuri@med.unc.edu
}

Received 15 November 2010; Revised 24 February 2011; Accepted 26 February 2011

Academic Editor: Roberto Lanes

Copyright (C) 2011 Mala Puri et al. This is an open access article distributed under the Creative Commons Attribution License, which permits unrestricted use, distribution, and reproduction in any medium, provided the original work is properly cited.

\begin{abstract}
Background. It is well acknowledged that glucocorticoid (GC) replacement can unmask diabetes insipidus (DI) in subjects with hypopituitarism. Objective. To increase the awareness and monitoring for transient and symptomatic DI in children with partial hypopituitarism during periods in which increased GC needs are required. Methods/Case. A 2-month-old female infant with septo-optic dysplasia (SOD; on thyroid and maintenance GC replacement therapy at $8 \mathrm{mg} / \mathrm{m}^{2} /$ day) developed transient DI during 2 separate episodes of stress (one hypothermia, one febrile) when stress dosing of GC $\left(25 \mathrm{mg} / \mathrm{m}^{2} /\right.$ day) was instituted. Conclusion. Children not diagnosed with DI during initial evaluation for hypopituitarism may benefit from rescreening of serum sodium levels during acute periods of stress that demand "stress" GC dosing. This will permit treatment and/or increased vigilance for ensuing permanent DI.
\end{abstract}

\section{Background}

Septo-optic dysplasia (SOD) is a malformation syndrome in which at least $50 \%$ of children have associated hypopituitarism $[1,2]$. This condition includes agenesis of the septum pellucidum, hypoplasia, or aplasia of the optic nerves and chiasm that results in various degrees of visual impairment and abnormality of the hypothalamus causing secondary hypopituitarism [3]. Diabetes insipidus (DI) is a condition characterized by excretion of large volumes of dilute urine secondary to either a deficiency in the production/release of the hormone arginine vasopressin (AVP) that is synthesized in the hypothalamus and transported and stored in the posterior pituitary for release in response to a rise in plasma concentrations of osmotically active substances or an impaired response or resistance to AVP at the level of the kidney (nephrogenic DI, 4). The most common form of DI is due to a primary deficiency of AVP. Central DI due to midline brain abnormalities may also be accompanied by a defective thirst mechanism [4].

Here we present an infant in whom DI was not present during maintenance GC replacement but was unveiled during two episodes in which "triple stress GC dosing" was accompanied by temporary DI.

\section{Methods/Case}

Patient is a 2-month-old female with SOD diagnosed in the newborn period secondary to hypoglycemia and hypotonia. SOD was confirmed by both MRI and ophthalmologic exam. Hypopituitarism manifested with central hypothyroidism and hypoadrenalism such that her medications at presentation included thyroid supplementation $(37.5 \mathrm{mcg}$ or $10 \mathrm{mcg} / \mathrm{kg} /$ day $)$ and hydrocortisone $\left(8 \mathrm{mg} / \mathrm{m}^{2} /\right.$ day $)$.

On day of life no. 70, she presented to the ED at the OSH with apnea and lethargy (which responded to stimulation), dehydration, and hypothermia (temperature $33.78^{\circ} \mathrm{C}$ ). She underwent a septic workup, including urine and blood cultures, that were negative. Of note, her initial serum sodium ( $\mathrm{Na}$ ) was $153 \mathrm{mmol} / \mathrm{L}$ (range $135-145 \mathrm{mmol} / \mathrm{L}$ ). She received a dose of ceftriaxone and an initial stress dose GC of $25 \mathrm{mg}\left(100 \mathrm{mg} / \mathrm{m}^{2}\right)$ at the OSH and then transferred to our PICU. Repeat serum Na was then $155 \mathrm{mmol} / \mathrm{L}$, and she was treated with a normal saline intravenous (IV) fluid bolus 


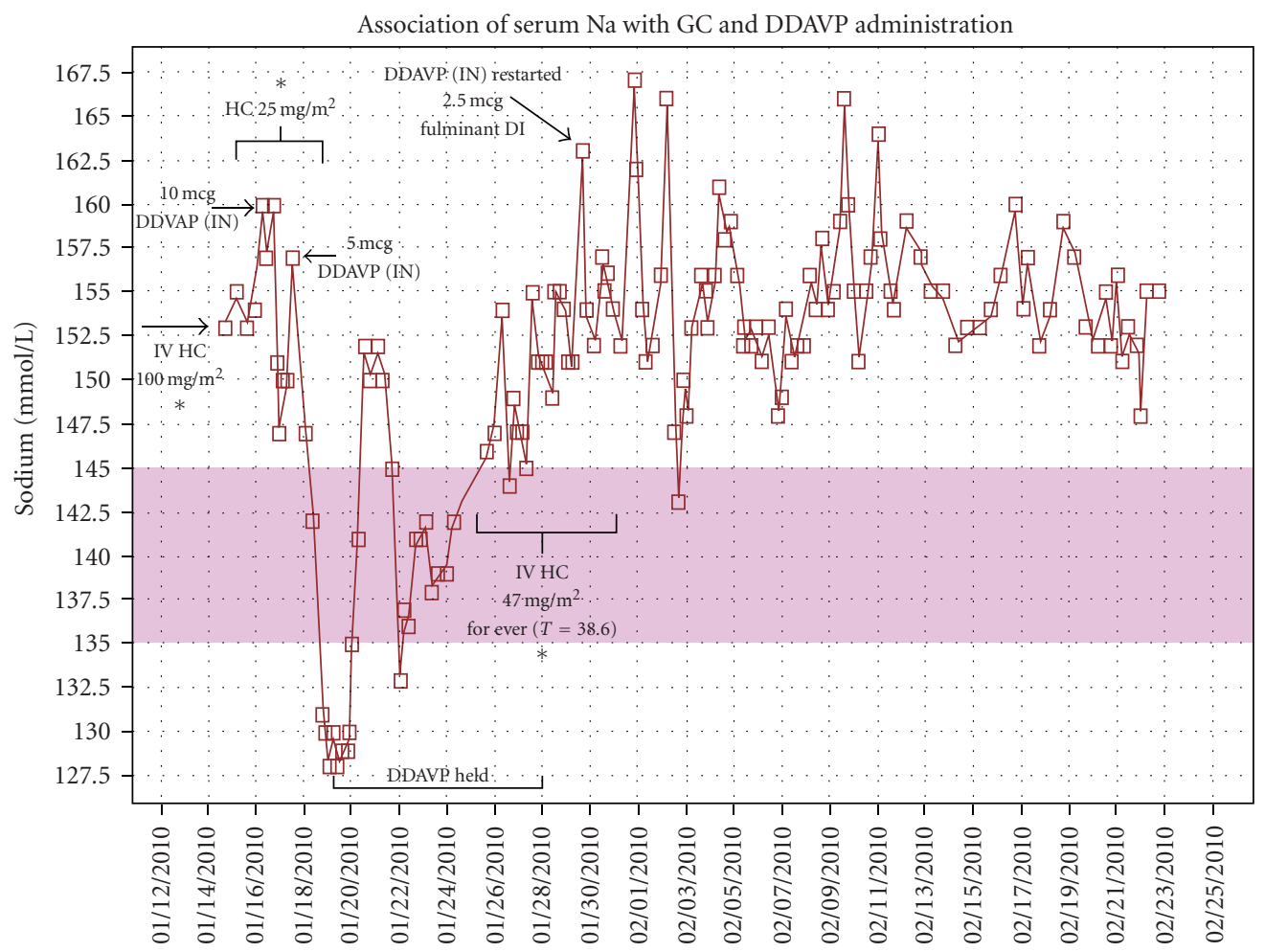

FIGURE 1: Association of serum Na levels with (1) GC dosing and then (2) DDAVP administration over time. The effect of stress HC dosing and DDAVP on serum Na levels in a patient with SOD. As shown on the $y$ axis, serum $\mathrm{Na}$ (levels mmol/L, $\square$ ) rise on each occasion in which $\mathrm{HC}$ dosing is increased over maintenance dosing $(*)$, consistent with an unmasking of DI in child with partial hypopituitarism over time ( $x$ axis). Note that during a prolonged afebrile period and maintenance dosing, serum Na levels remained in the normal range (pink bar). In this patient, the transient DI during febrile episodes and GC stress dosing was then followed by progression to permanent DI with serum $\mathrm{Na}$ of $163 \mathrm{mmol} / \mathrm{L}, \mathrm{U}_{\mathrm{SG}}$ of 1.005 , and an AVP level of $<0.6 \mathrm{pg} / \mathrm{mL}$, and patient was then maintained on DDAVP. Please note that the DDAVP doses were intranasal (IN) preparations given orally, so the effective DDAVP dose is 1/10 of the listed dose.

and then maintained on D5.5 NS at maintenance for a 12hour period. Her Na rose to 160, and she was given DDAVP (10 mcg of intranasal solution given orally; effective dose of $1 \mathrm{mcg}$ ). During this time she continued GC stress dosing of $2.3 \mathrm{mg}$ hydrocortisone every 8 hours (at $25 \mathrm{mg} / \mathrm{m}^{2} /$ day; see Figure 1).

Approximately 10 hours later, while on oral feeds and no supplemental IVF, her Na level dropped to 147 (rate of $1.2 \mathrm{mmol} /$ hour). Oral feeds continued without DDAVP and, after 17 hours, her Na level again rose to $157 \mathrm{mmol} / \mathrm{L}$. A second lower dose of DDAVP (effective dose of only $0.5 \mathrm{mcg}$ ) was then given as she appeared dehydrated and was tachycardic. Accurate urine output was not obtained as patient had not been catheterized. Surprisingly, this second dose resulted in an acute drop in her $\mathrm{Na}$ to $130 \mathrm{mmol} / \mathrm{L}$ over twelve hours $(2.25 \mathrm{mmol} / \mathrm{hour})$ and was accompanied by seizure activity. The patient was on oral feeds by this time, with IVF at $2 \mathrm{~mL} / \mathrm{hr}$ to maintain IV patency. Her serum sodium levels normalized to $136-142 \mathrm{mmol} / \mathrm{L}$ over the following 18-hour period with fluid restriction.

Once normothermic, she was returned to her maintenance GC dose, and, of note, no subsequent doses of DDAVP were required during this 6 -day period. At this time, a modified water deprivation test was performed and, at time of 15 hours, the patient's serum Na remained normal at 141 with a $\mathrm{U}_{\mathrm{SG}}$ of 1.014, arguing against fulminant DI.

A subsequent febrile episode (temp $38.6^{\circ} \mathrm{C}$ ) led to reinstitution of stress GC dosing (at $47 \mathrm{mg} / \mathrm{m}^{2} /$ day) with repeat blood and urine cultures being negative. Again, her serum $\mathrm{Na}$ increased to a peak of $163 \mathrm{mmol} / \mathrm{L}$ and was accompanied by a $U_{S G}$ of 1.005 , a weight loss of $1.72 \mathrm{~kg}$ as well as an AVP level that was notably undetectable at $<0.6 \mathrm{pg} / \mathrm{mL}$ (Mayo Clinic, Rochester, $\mathrm{MN}$ ), supporting the diagnosis of another episode of "unmasking" of DI. Consequently, DDAVP was reinstituted, albeit at a markedly conservative dose of $2.50 \mathrm{mcg}$ of IN preparations given orally (effective dose of $0.25 \mathrm{mcg}$ ) that successfully maintained her Na levels within a range of $145-155 \mathrm{mmol} / \mathrm{L}$. Interestingly, she has been maintained on this dose since that time, given that her "transient" episodes seen during the increased GC exposure ultimately progressed to permanent, although likely "partial," DI.

\section{Results/Conclusions}

Although the "unmasking of DI" upon institution of GC replacement in children with pituitary insufficiency is well recognized, the mechanism of the sequelae is less well delineated. Both a GC-induced decrease in AVP release 
as well as inhibition of action at the level of the kidney has both been reported [5]. For example, Yamada et al. [6] demonstrated that corticotropin releasing hormone (CRH) administration augmented plasma arginine vasopressin (AVP) in response to an osmotic stimulus. The authors also reported that cortisol administration to patients with hypopituitarism decreased plasma AVP response to the osmotic stimulus [6]. Consequently, the authors deduced that the effect of cortisol was due to a central suppression of the AVP response to an osmotic stimulus. Furthermore, given that basal plasma renin activity, plasma aldosterone, plasma osmolality, hematocrit, body weight, mean blood pressure, and heart rate were similar in subjects with and without cortisol administration, the authors proposed that the effect of cortisol may be related to suppression of AVP release in response to osmotic stimuli. Furthermore, when the authors then pretreated the patients with DI with $20 \mathrm{mg}$ of hydrocortisone, they found no significant change in the basal AVP levels; however, the maximal AVP response to an osmotic stimulus was significantly attenuated, thereby suggesting that $\mathrm{CRH}$ suppression by GCs was via inhibition of the AVP release [6]. In contrast, Linas et al. [7] measured total urine volume and $\mathrm{U}_{\mathrm{SG}}$ in adrenalectomized rats and found that GC deficiency impairs renal water excretion. Moreover, Linas and colleagues demonstrated that GCtreated rats had a significantly higher urine flow (GFR) [7].

To date, no cases have been reported in which DI was induced only when greater than maintenance dosing of GCs were given. In our patient, DI was unmasked initially during a presumed viral illness only during episodes where stress dose GCs were required, suggesting a mild/partial DI, especially given the markedly low dose of DDAVP required to control her DI despite unmeasurable endogenous AVP levels during period of elevated serum $\mathrm{Na}$ levels and low $\mathrm{U}_{\mathrm{SG}}$. Interestingly, after the continued need for stress GC dosing, permanent, although likely still partial, DI evolved with low dosing requirement, suggesting that we may have unmasked the progression of natural development to DI that was occurring but was brought to medical attention during her periods of increased GC requirements.

This case supports, therefore, that, in children who have not been diagnosed with DI during their initial evaluation for hypopituitarism (e.g., SOD), rescreening of serum $\mathrm{Na}$ levels (along with parallel $\mathrm{U}_{\mathrm{SG}}$ or osm along with body weight monitoring) during episodes of acute stress and concomitant increased GC dosing may, indeed, be clinically relevant by unveiling a partial/complete DI. Such vigilance could then obviate symptomatic DI, particularly in a young infant or in a child whose thirst mechanism may be either difficult to assess (since feeds are still formula) or may be impaired. It is also important to note, since DI could still be partial as it was in our patient, that the dosing of DDAVP is done conservatively and only when the patient has clinical signs of DI (e.g., hypernatremia accompanied by dehydration and/or weight loss). Finally, the DI should also be viewed as transient/episodic until permanent DI has been declared.

\section{Abbreviations}

AVP: Arginine vasopressin

DDAVP: Desmopressin acetate

DI: Diabetes insipidus

ED: $\quad$ Emergency Department

GC: Glucocorticoid

HC: Hydrocortisone

osm: Osmolarity

OSH: Outside Hospital

PICU: Pediatric Intensive Care Unit

SOD: Septo-optic dysplasia

$\mathrm{U}_{\mathrm{SG}}$ : Urine specific gravity.

\section{Acknowledgment}

This paper was classified as "exempt" by the IRB at the University of North Carolina and was supported by NIH Fellow Training Grant T32-DK07129 for Dr. Anita Azam.

\section{References}

[1] M. M. Grumbach and P. D. Gluckman, "The human fetal hypothalamic and pituitary: the maturation of neuroendocrine mechanisms controlling the secretion of fetal pituitary growth hormone, prolactin, gonadotropins, adrenocorticotropinrelated peptides and thyrotropin," in Maternal and Fetal Endocrinology, D. Tuclchinsky and A. B. Little, Eds., pp. 193-261, W. B. Saunders, Philadelphia, Pa, USA, 1994.

[2] S. L. Kaplan and M. M. Grumbach, "Pathophysiology of GH deficiency and other disorders of GH metabolism," in Problems in Pediatric Endocrinology, Serono Symposia, C. LacCauza and A. W. Root, Eds., vol. 32, p. 45, Academic Press, London, UK, 1980.

[3] C. Migeon and R. Lanes, "Adrenal cortex: hypo- and hyperfunction," in Pediatric Endocrinology, F. Lifshitz, Ed., pp. 147-173, Marcel Dekker, New York, NY, USA, 2003.

[4] A. Srivasta, J. Majzoub, and M. Kappy, "Posterior pituitary and disorders of water metabolism," in Pediatric Practice Endocrinology, M. Kappy, Ed., pp. 77-90, McGraw-Hill, New York, NY, USA, 2010.

[5] C. Rabadan-Diehl and G. Aguilera, "Glucocorticoids increase vasopressin V1b receptor coupling to phospholipase C," Endocrinology, vol. 139, no. 7, pp. 3220-3226, 1998.

[6] K. Yamada, Y. Tamura, and S. Yoshida, "Effect of administration of corticotropin-releasing hormone and glucocorticoid on arginine vasopressin response to osmotic stimulus in normal subjects and patients with hypocorticotropinism without overt diabetes insipidus," Journal of Clinical Endocrinology and Metabolism, vol. 69, no. 2, pp. 396-401, 1989.

[7] S. L. Linas, T. Berl, and G. L. Robertson, "Role of vasopressin in the impaired water excretion of glucocorticoid deficiency," Kidney International, vol. 18, no. 1, pp. 58-67, 1980. 